[Chem. Pharm. Bull.

33( 6 )2560-2563(1985)]

\title{
Change in Digitonin-Stimulated Superoxide Anion Production by Guinea Pig Polymorphonuclear Leukocytes in Response to the Presence of Calcium Ion
}

\author{
Naoki OKamura, ${ }^{*}$ Tadao OKamoto, and Sadahiko Ishibashi \\ Department of Physiological Chemistry, Hiroshima University School of Medicine, \\ Minami-ku, Hiroshima 734, Japan
}

(Received August 30, 1984)

\begin{abstract}
Treatment of guinea pig polymorphonuclear leukocytes with digitonin in the presence of $\mathrm{Ca}^{2+}$ induced marked stimulation of superoxide anion production. Removal of $\mathrm{Ca}^{2+}$ from the incubation medium by addition of ethyleneglycolbis ( $\beta$-aminoethyl ether) $N, N, N^{\prime}, N^{\prime}$-tetraacetate (EGTA) either before or after the digitonin addition suppressed the stimulation of the superoxide anion production. Furthermore, readdition of $\mathrm{Ca}^{2+}$ in excess of the added EGTA restored the stimulatory effect of digitonin on the superoxide anion production in the leukocytes. These findings suggest the existence of reversible regulation of the digitonin-stimulated superoxide anion production by $\mathrm{Ca}^{2+}$.
\end{abstract}

Keywords_— polymorphonuclear leukocyte; superoxide anion production; digitonin; calcium ion; cell membrane

It is well known that active oxygen metabolites, such as superoxide anion, hydroxyl radical, hydrogen peroxide, singlet oxygen, etc., produced at the time of phagocytosis in polymorphonuclear leukocytes (PMNL) play an important role in the bactericidal function. Production of these active oxygen metabolites can also be induced by various membraneperturbing agents, such as cytochalasins, lectins, surfactants, etc. ${ }^{1-3)}$ The nicotinamide adenine dinucleotide phosphate (NADPH) oxidase system in the plasma membrane of PMNL is principally responsible for the production of superoxide anion, which is assumed to be a primary product among the active oxygen metabolites. ${ }^{4)}$ It is inferred that stimulation either by phagocytosis or by these membrane-perturbing agents triggers the activation of this enzyme system in the membrane to produce superoxide anion. However, the process of activation is not well understood. As one possible mechanism, involvement of $\mathrm{Ca}^{2+}$ has been reported in the stimulation of the superoxide anion-producing system by some membrane-perturbing agents. ${ }^{5,6)}$

In this study, we examined the modulating effect of $\mathrm{Ca}^{2+}$ on the stimulation of superoxide anion production by digitonin in guinea pig PMNL. The stimulation was suppressed by the removal of $\mathrm{Ca}^{2+}$, and was restored by the subsequent addition of $\mathrm{Ca}^{2+}$.

\section{Materials and Methods}

Cytochrome c (type III, horse heart) was purchased from Sigma Chemical Co. Other chemicals were products of special grade from standard commercial sources.

Guinea pig PMNL were obtained from the peritoneal cavity $12-18 \mathrm{~h}$ after the intraperitoneal injection of $30 \mathrm{mg} / \mathrm{kg}$ of casein as a $10 \%$ neutral solution, as reported previously. ${ }^{7)}$

Superoxide anion production by PMNL was measured on the basis of reduction of ferricytochrome cy the anion produced. ${ }^{8)}$ PMNL $\left(2-2.5 \times 10^{6}\right)$ were suspended in Hanks' solution containing 8 mM piperazine- $N, N^{\prime}$-bis $(2-$ ethanesulfonic acid) ( $\mathrm{pH}$ 7.3), and the agents were added to the suspension as indicated. The mixture was incubated at $37^{\circ} \mathrm{C}$, and ferricytochrome $\mathrm{c}$ was finally added to a concentration of $0.1 \mathrm{~mm}$. The mixture was further incubated for 2 
or $10 \mathrm{~min}$ to measure the reduction of ferricytochrome $\mathrm{c}$ by superoxide anion produced by PMNL in response to the stimulation. The reaction was stopped by chilling, and the mixture was centrifuged at $100 \times g$ and $4{ }^{\circ} \mathrm{C}$ for $10 \mathrm{~min}$ to precipitate PMNL. Reduced cytochrome $\mathrm{c}$ in the supernatant was measured on the basis of the increase in absorbance at $550 \mathrm{~nm}$.

Release of lactate dehydrogenase from PMNL during the incubation was examined as an index of leakage of the cellular content. After centrifugation of the incubation mixture to precipitate PMNL, the activity of this enzyme in the supernatant was measured by a conventional method. ${ }^{9)}$ The value is expressed as a percentage of the released activity to the total activity including the activity in PMNL.

\section{Results}

Inhibition of Digitonin-Stimulated Superoxide Anion Production by Removal of $\mathrm{Ca}^{2+}$

Addition of digitonin to the incubation medium for guinea pig PMNL stimulated superoxide anion production. The stimulation was observed over a rather narrow range of digitonin concentration (Fig. 1, open circles). The stimulatory effect of digitonin was scarcely observed when $\mathrm{Ca}^{2+}$ contained in Hanks' solution $(1.28 \mathrm{~mm})$ was removed by addition of $1.5 \mathrm{~mm}$ ethyleneglycolbis ( $\beta$-aminoethyl ether) $N, N, N^{\prime}, N^{\prime}$-tetraacetate (EGTA) 10 min before the addition of digitonin (Fig. 1, closed circles), indicating an essential requirement for $\mathrm{Ca}^{2+}$ for the stimulation of the superoxide anion-producing system by digitonin. ${ }^{6)}$

On the other hand, superoxide anion production stimulated by $8 \mu \mathrm{M}$ digitonin was decreased by $73 \%$ when EGTA was added $10 \mathrm{~min}$ after the addition of digitonin (Fig. 2). The result suggests that $\mathrm{Ca}^{2+}$ is necessary not only for the triggering of the superoxide anionproducing system by digitonin, as is generally accepted, but also for the maintenance of the stimulated state of this system.

In the time course study, inhibition of the digitonin-stimulated superoxide anion production by EGTA was observed not immediately, but from $6-8 \mathrm{~min}$ after the addition of EGTA (Fig. 3), indicating that some time is required for EGTA to remove intracellular $\mathrm{Ca}^{2+}$. In relation to this finding, it was noticed that the concentration of digitonin required to stimulate maximally the superoxide anion production coincided with that required to cause a release of lactate dehydrogenase from PMNL. Thus, stimulation of the superoxide anionproducing system by digitonin may be accompanied by an increase in the permeability of the membrane, so that intracellular $\mathrm{Ca}^{2+}$ concentration can be decreased by extracellularly added

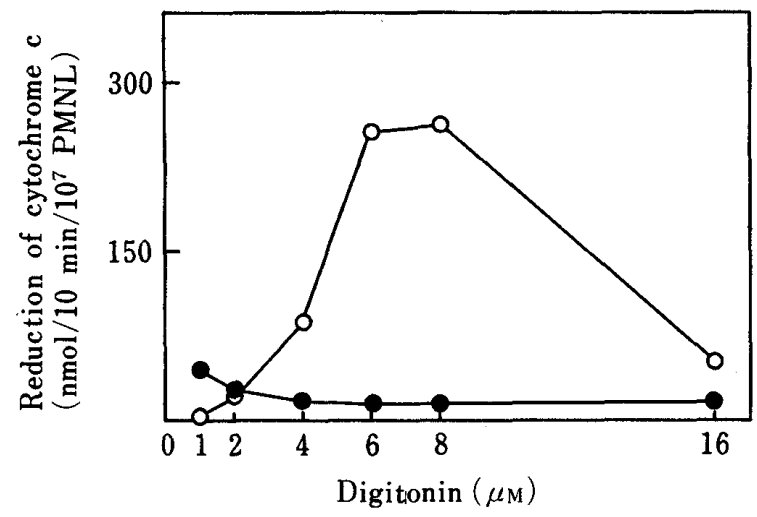

Fig. 1. Digitonin-Stimulated Superoxide Anion Production by PMNL in the Presence and Absence of $\mathrm{Ca}^{2+}$

Open circles: after incubation of PMNL for $20 \mathrm{~min}$ with the indicated concentrations of digitonin, ferricytochrome $\mathrm{c}$ reduction (corresponding to superoxide anion production) was measured for $10 \mathrm{~min}$ in the presence of digitonin. Closed circles: PMNL were incubated with $1.5 \mathrm{~mm}$ EGTA before the addition of digitonin. Other details were the same.

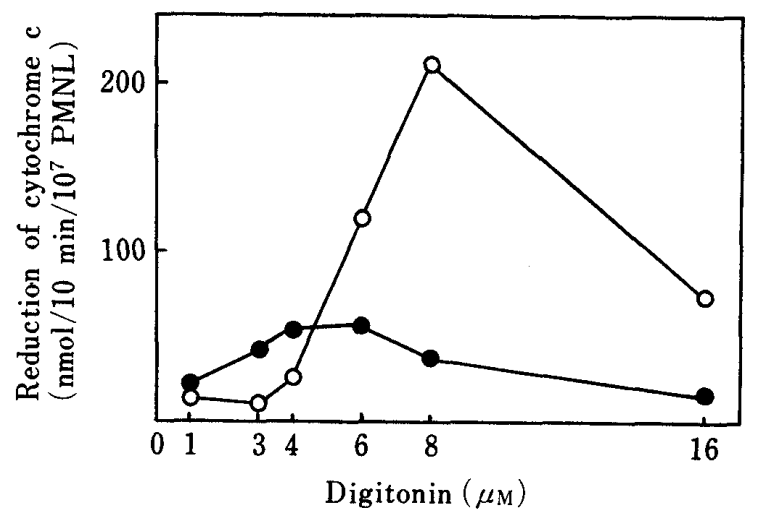

Fig. 2. Effect of EGTA Added after Stimulation of Superoxide Anion Production by Digitonin

Open circles: the same as for Fig. 1. Closed circles: PMNL were incubated with $8 \mu \mathrm{M}$ digitonin alone for $10 \mathrm{~min}$, and with digitonin and $1.5 \mathrm{~mm}$ EGTA for another $10 \mathrm{~min}$. Then, superoxide anion production was measured for $10 \mathrm{~min}$. 


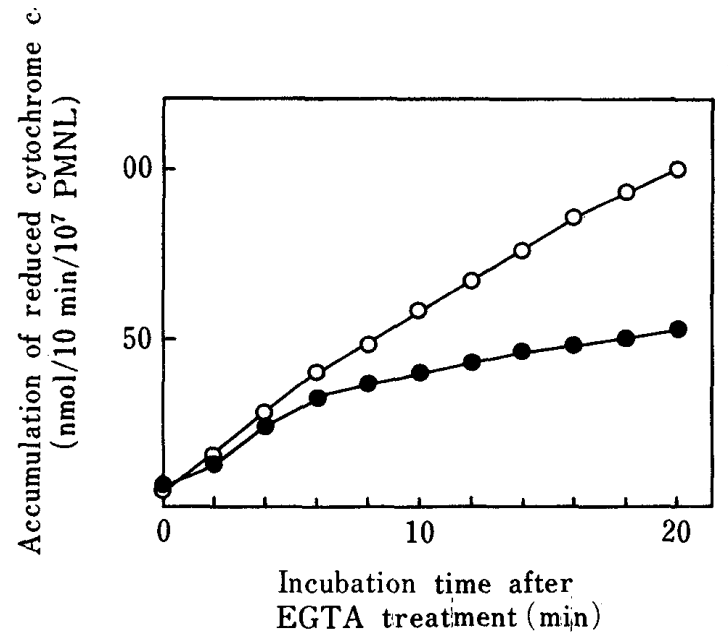

Fig. 3. Time Required for the Appearance of the Suppressive Effect of EGTA on Digitonin$\mathrm{Ca}^{2+}$-Stimulated Superoxide Anion Production

PMNL were incubated with $8 \mu \mathrm{M}$ digitonin for first $10 \mathrm{~min}$, and then with digitonin and $1.5 \mathrm{mM}$ EGTA for the period indicated on the abscissa. After that, superoxide anion production was measured for $2 \mathrm{~min}$. The results are expressed as accumulated superoxide anion production. Open circles: without EGTA. Closed circles: with EGTA.

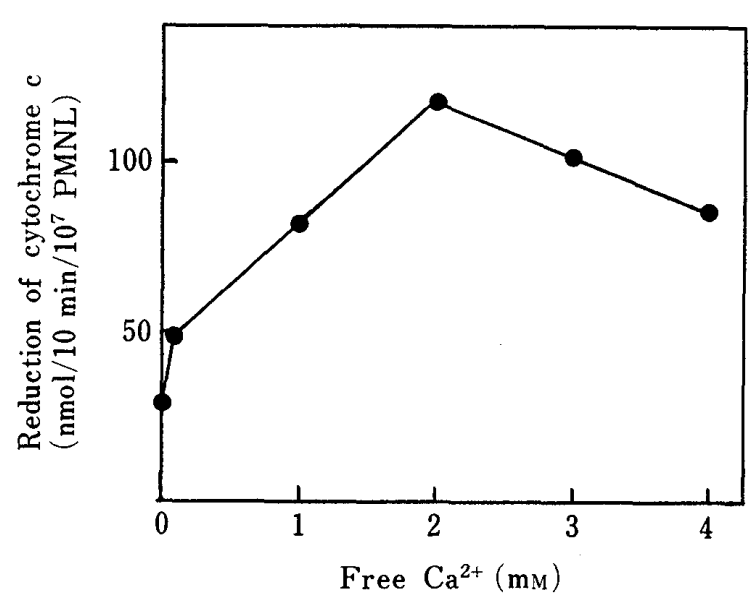

Fig. 4. Reactivation of Superoxide Anion Production by Addition of $\mathrm{Ca}^{2+}$ to EGTATreated PMNL

For experimental details, see the text. Free $\mathrm{Ca}^{2+}$ concentration indicates the difference between total $\mathrm{Ca}^{2+}$ concentration and EGTA concentration. Superoxide anion production in control PMNL, i.e. with $1 \mathrm{mM} \mathrm{Ca}^{2+}$ and without EGTA, was $173 \mathrm{nmol} / 10 \mathrm{~min} /$ $10^{7}$ cells.

EGTA with some time lag.

\section{Reactivation by $\mathrm{Ca}^{2+}$ of Superoxide Anion-Producing System of PMNL Pretreated with Digitonin and EGTA}

Addition of $\mathrm{Ca}^{2+}$ to incubation medium for PMNL, in which superoxide anion production had first been stimulated by digitonin and $\mathrm{Ca}^{2+}$ but then suppressed by $\mathrm{Ca}^{2+}$ removal with EGTA, caused reactivation of the producing system (Fig. 4). In this experiment, PMNL were treated with $6 \mu \mathrm{M}$ digitonin for $10 \mathrm{~min}$ in the presence of $1.28 \mathrm{mM} \mathrm{Ca}^{2+}$. Then $1.5 \mathrm{~mm}$ EGTA was added, and the incubation was continued for another $10 \mathrm{~min}$. After that, the indicated concentration of $\mathrm{Ca}^{2+}$ was added again, and the mixture was incubated for a further $10 \mathrm{~min}$. Superoxide anion production in these digitonin-EGTA-Ca ${ }^{2+}$-treated PMNL was measured. As shown in this figure, addition of $2 \mathrm{mM} \mathrm{Ca}^{2+}$ was most effective in reactivating the superoxide anion-producing system after the $\mathrm{Ca}^{2+}$ removal. It is likely, in view of these results, that the stimulatory effect of digitonin on the superoxide anionproducing system is reversibly regulated by $\mathrm{Ca}^{2+}$

\section{Discussion}

It is now widely accepted that superoxide anion production is an important mechanism in the bactericidal function of PMNL. However, since the superoxide anion is quite toxic to cells, not only to the producing cells themselves but also to the surrounding cells, and may induce inflammation, some mechanism should exist to minimize the harmful effect by preventing the overproduction of this active oxygen species. Such a regulatory mechanism for the superoxide anion-producing system, however, has not been elucidated as yet. As regards the stimulation of the producing system by digitonin, it was reported that addition of EGTA or $N$-ethylmaleimide after digitonin treatment was unable to suppress the already enhanced production of superoxide anion. ${ }^{6)}$ This finding seems to indicate that the production continues straightforwardly after the stimulation. On the contrary, we found in the present study that 
addition of EGTA after stimulation by digitonin was effective in suppressing the superoxide anion production in guinea pig PMNL. In addition, the production was stimulated again by readdition of excess $\mathrm{Ca}^{2+}$ after the treatment with EGTA. These findings indicate that the superoxide anion-producing system stimulated by digitonin is reversibly regulated $\mathrm{Ca}^{2+}$ These results seem to be in line with those reported for the reversibility of superoxide anion production stimulated by sodium fluoride ${ }^{10)}$ and concanavalin A. ${ }^{11)}$

Concerning the effect of $\mathrm{Ca}^{2+}$ on the digitonin-stimulated superoxide anion production, the reason for the discrepancy between the previously reported results ${ }^{6)}$ and ours is not clear. However, one of the reasons may be a difference in the time of testing after the addition of digitonin and EGTA. We observed superoxide anion production $10-30 \mathrm{~min}$ after the treatment of PMNL with digitonin. In addition, the inhibitory effect of EGTA was found 68 min after the addition (Fig. 3), and release of lactate dehydrogenase from PMNL was increased at almost the same concentration of digitonin as that which stimulated superoxide anion production. Thus, the cell membrane of PMNL might have been perturbed enough to allow the permeation of $\mathrm{Ca}^{2+}$ as a result of the digitonin treatment in our study. Such a change in the cell membrane may be a prerequisite for the ability of EGTA to remove the intracellular $\mathrm{Ca}^{2+}$, and may require about $6-8 \mathrm{~min}$. Thus, if superoxide anion production is measured shortly after the addition of these agents, as in the previous paper, ${ }^{6)}$ the effect of EGTA not be observable.

\section{References}

1) A. Nakagawara, Y. Shibata, K. Takeshige, and S. Minakami, Exptl. Cell Res., 101, 225 (1976).

2) M. F. Tsan and P. A. McIntyre, J. Exp. Med., 143, 1308 (1976).

3) H. J. Cohen and M. E. Chovaniec, J. Clin. Invest., 61, 1081 (1978).

4) T. G. Gabig and B. M. Babior, J. Biol. Chem., 254, 9070 (1979).

5) T. Matsumoto, K. Takeshige, and S. Minakami, Biochem. Biophys. Res. Commun., 88, 974 (1979).

6) H. J. Cohen and M. E. Chovaniec, J. Clin. Invest., 61, 1088 (1978).

7) N. Okamura and S. Ishibashi, J. Biochem. (Tokyo), 91, 1725 (1982).

8) B. M. Babior, R. S. Kipnes, and J. T. Curnutte, J. Clin. Invest., 52, 741 (1973).

9) J. B. Neiland, "Methods in Enzymology," Vol. I, ed. by S. P. Colowick and N. O. Kaplan, Academic Press, New York, 1955, pp. 449-454.

10) J. T. Curnutte, B. M. Babior, and M. L. Karnovsky, J. Clin. Invest., 63, 637 (1979).

11) H. J. Cohen, M. E. Chovaniec, M. K. Wilson, and P. E. Newburger, Blood, 60, 1188 (1982). 